http://jmscr.igmpublication.org/home/

ISSN (e)-2347-176x ISSN (p) 2455-0450

crossref DOI: https://dx.doi.org/10.18535/jmscr/v7i12.114

\title{
Correlation of Left Ventricular Mass with Biochemical Variables in Hypertensive Subjects
}

Authors

\section{Dr Chaitrali Gawde ${ }^{1 *}$, Dr Sanjay Agrawal ${ }^{2}$, Dr Amrit Kejriwal ${ }^{3}$}

${ }^{1}$ Third year Resident, ${ }^{2}$ Senior Resident, ${ }^{3}$ Professor

${ }^{1,2,3}$ Department of General Medicine at MGM Medical College and Hospital, Kamothe, Navi Mumbai

*Corresponding Author

Dr Chaitrali Gawde

MBBS, Third year Resident in the Department of General Medicine at MGM Medical College and Hospital, Kamothe, Navi Mumbai, India

\section{Introduction}

\section{Hypertension}

The amount of blood pumped by the heart and also resistance offered to the flow of blood in the arteries determines the blood pressure in our body. When the long term force of the blood is very high so that the health problems may occur like heart diseases, the condition is known as high blood pressure or hypertension.

There are mainly two types of hypertension i.e.: Primary (essential hypertension) - when there is no visible cause of hypertension and which tends to develop over a period of time.

Secondary hypertension - hypertension is caused due to some underlying condition. ${ }^{1}$

Diastolic Blood Pressure- "Diastolic" comes from the Greek word "diastole" meaning "a drawing apart." It is the pressure that exerted by blood on the walls of the arteries through which it flows during ventricular relaxation. Normal range is $60-80 \mathrm{~mm}$ of $\mathrm{Hg}$ in adults. It reflects the minimum pressure in the arteries.
Systolic Blood Pressure- "Systolic" comes from the Greek word "systole" meaning "a drawing together or a contraction." It is the pressure that exerted by blood on the walls of the arteries through which it flows during ventricular contraction. Normal range of systolic blood pressure is $90-120 \mathrm{~mm}$ of $\mathrm{Hg}$ in adults. It reflects the maximum pressure exerted on the arteries.

\section{Left Ventricular Hypertrophy}

When the left pumping chamber of the heart stops functioning properly i.e. its normal pumping action is hampered due to the thickening, the condition is known as left ventricular hypertrophy. Sometimes the heart muscles overwork due to problems like aortic stenosis. Due to this, thickening of heart muscles may happen along the inner walls of heart. Due to this thickening, left chamber may become weak, stiff and it may lose its elasticity also. Combining all this, healthy blood flow may stop resulting in heart diseases. ${ }^{2}$

Left ventricular hypertrophy increase risk of morbidity and mortality substantially. ${ }^{345}$ 
Investigating the factors which affect Left Ventricular Hypertrophy is essential simply because of reason that it is one of the major risk factors leading to extremely dangerous heart diseases and even sudden death at early ages. The studies have shown that left ventricular hypertrophy exists in early ages which can lead to early age heart disease which leads to increase in morbidity and mortality.

It is a well-known fact that the mechanical stress of blood pressure overload mediates left ventricular hypertrophy in the body but the studies have also shown that various neurohormonal substances that independently exert trophic effects on myocytes and nonmyocytes in the heart can lead to left ventricular hypertrophy. ${ }^{6}$

In this study we are studying correlation of left ventricular mass (LVM) with biochemical variables in hypertensive subjects.

\section{Aims and Objectives}

To study the correlation of left ventricular mass with biochemical variables in hypertensive subjects.

\section{Material S and Methods}

200 patients visiting Medicine OPD and patients admitted in the Medicine wards of MGM Institute of Health Sciences, Kamothe, Navi-Mumbai during the period of $1^{\text {st }}$ January, 2017 to $31^{\text {st }}$ May, 2018 was taken for study.

The data was collected from the patients through detailed clinical history, clinical examination and relevant investigations.

Following set of investigations were conducted for the selected patients:

- Blood pressure, Pulse pressure, Mean Arterial Pressure, Heart rate

- Serum-sodium $\left(\mathrm{Na}^{+}\right)$, potassium $\left(\mathrm{K}^{+}\right)$, creatinine, uric acid (UA)

- FBS(Fasting blood sugar), PPBS(Post Prandial blood sugar)

- Lipid profile

\begin{tabular}{|l|l|}
\hline CHL & Cholesterol \\
\hline TG & Triglycerides \\
\hline HDL & High Density Lipoproteins \\
\hline VLDL & Very Low Density Lipoproteins \\
\hline LDL & Low Density Lipoproteins \\
\hline
\end{tabular}

Left ventricular mass was calculated using the formula that has been shown to yield values closely related $(r=0.90)$ to necropsy LV weight and which has good inter-study reproducibility.

LVM $($ ASE $)=0.8\{1.04[($ IVSd + LVIDd + PWD $)^{3}-$ LVIDd $\left.\left.^{3}\right]\right\}+0.6 \mathrm{~g}$

Traditionally, LV has been classified into four mutually exclusive patterns according to LV geometry assessed by RWT and the presence or absence of LVH defined by an LVM index $>115$ $\mathrm{g} / \mathrm{m}^{2}$ for men or $>95 \mathrm{~g} / \mathrm{m}^{2}$ for women. ${ }^{7}$ Indexation of LVM to height raised to an allometric exponent of $2.7\left(\mathrm{LVM} / \mathrm{height}^{2.7}\right)$, in comparison to BSA or height alone, has shown better predictive value for CVD outcomes, better detection of obesity-related LVH, and less variability of LVM among normal individuals. ${ }^{8,9}$

Normal Values ${ }^{10}$

LV mass Women 67-162 g

Men $88-224 \mathrm{~g}$

LV mass/BSA (g/m2)

Women 43-95 g/m ${ }^{2}\left(18-44 \mathrm{~g} / \mathrm{m}^{2.7}\right)$

Men $49-115 \mathrm{~g} / \mathrm{m}^{2}$ (20-48 $\left.\mathrm{gm}^{2.7}\right)$

LV hypertrophy was said to be present if LVM was greater than $51 \mathrm{~g} / \mathrm{m}^{2.7}$ in men or women. ${ }^{11}$

\section{Inclusion Criteria}

1) Patients above 18 years of age

2) Both males and females

3) Patients with hypertension [diagnosis of hypertension is based on systolic blood pressure of $\geq 140 \mathrm{mmHg}$ and diastolic blood pressure of $\geq 90 \mathrm{mmHg}$ or those on antihypertensive therapy].

4) Patients on antihypertensive medications

5) Consent to participate into the study

\section{Exclusion Criteria}

1) Previous history or symptoms of ischemic heart disease 
2) Echocardiography evidence of regional wall motion abnormalities

3) Established congestive heart failure
4) Hypertrophic cardiomyopathy, left bundle branch block, valvular heart diseases \& congenital heart diseases

5) Incomplete echocardiography reports

\section{Results}

Figure 1 Biochemical parameters of hypertensive subjects according to gender

\begin{tabular}{|l|c|c|c|c|c|c|}
\hline \multirow{2}{*}{} & \multicolumn{2}{|c|}{ Male $(\mathrm{n}=112)$} & \multicolumn{2}{c|}{ Female $(\mathrm{n}=88)$} & \multicolumn{2}{c|}{ Total $(\mathrm{n}=200)$} \\
\cline { 2 - 7 } & Mean & SD & Mean & SD & Mean & SD \\
\hline $\mathrm{Na}^{+}(\mathrm{mEq} / \mathrm{L})$ & 139.49 & 4.86 & 140.01 & 5.24 & 139.72 & 5.02 \\
\hline $\mathrm{K}^{+}(\mathrm{mEq} / \mathrm{L})$ & 3.98 & .39 & 4.01 & .30 & 3.99 & .36 \\
\hline Creatinine $(\mathrm{mg} / \mathrm{dl})$ & 1.11 & .47 & .99 & .35 & 1.06 & .43 \\
\hline Uric Acid (mg/dl) & 5.34 & 1.00 & 5.75 & 5.49 & 5.52 & 3.71 \\
\hline FBS $(\mathrm{mg} / \mathrm{dl})$ & 94.29 & 16.55 & 93.88 & 13.76 & 94.11 & 15.35 \\
\hline PPBS (mg/dl) & 132.24 & 18.86 & 130.52 & 18.99 & 131.49 & 18.89 \\
\hline CHL (mg/dl) & 192.98 & 32.27 & 194.47 & 21.50 & 193.64 & 27.99 \\
\hline TG $(\mathrm{mg} / \mathrm{dl})$ & 86.16 & 19.03 & 84.27 & 15.86 & 85.33 & 17.69 \\
\hline HDL (mg/dl) & 45.33 & 10.82 & 46.00 & 7.60 & 45.63 & 9.52 \\
\hline VLDL (mg/dl) & 26.26 & 8.36 & 30.98 & 9.67 & 28.34 & 9.24 \\
\hline LDL (mg/dl) & 102.46 & 30.69 & 103.70 & 29.49 & 103.01 & 30.10 \\
\hline
\end{tabular}

Figure 2 Graph showing mean $\mathrm{Na}^{+}$of hypertensive subjects according to gender

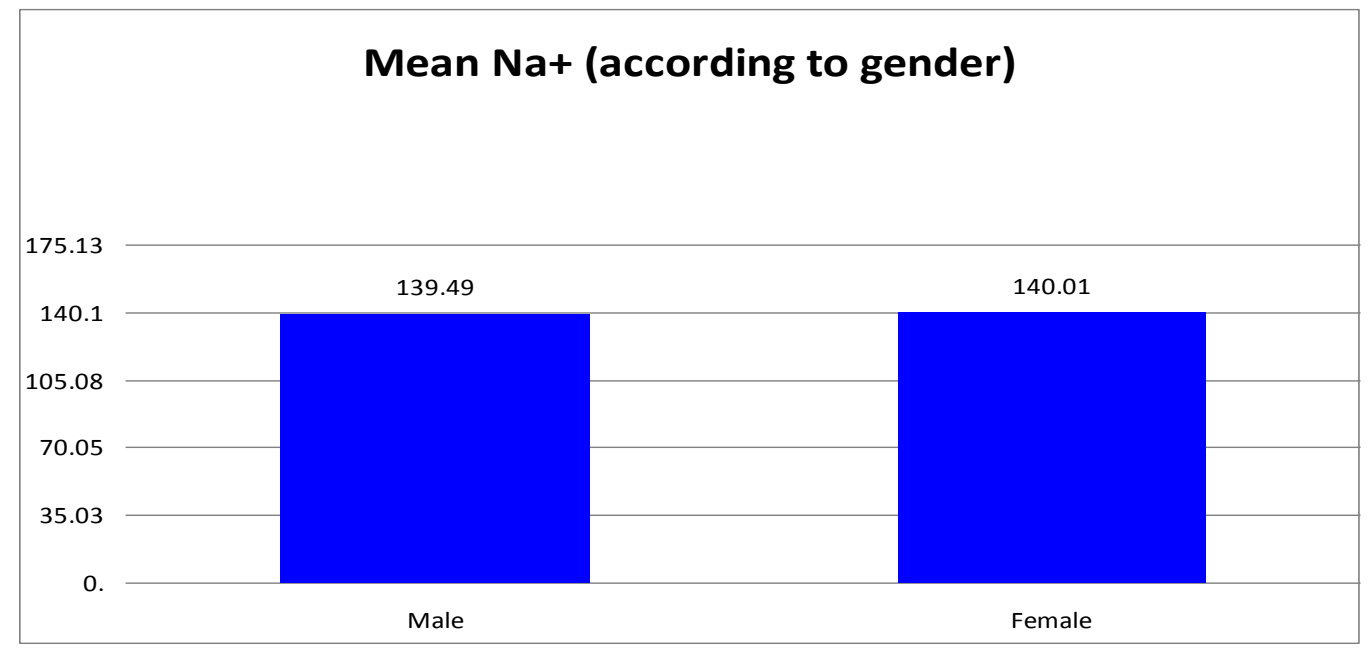

Figure 3 Graph showing mean $\mathrm{K}^{+}$of hypertensive subjects according to gender

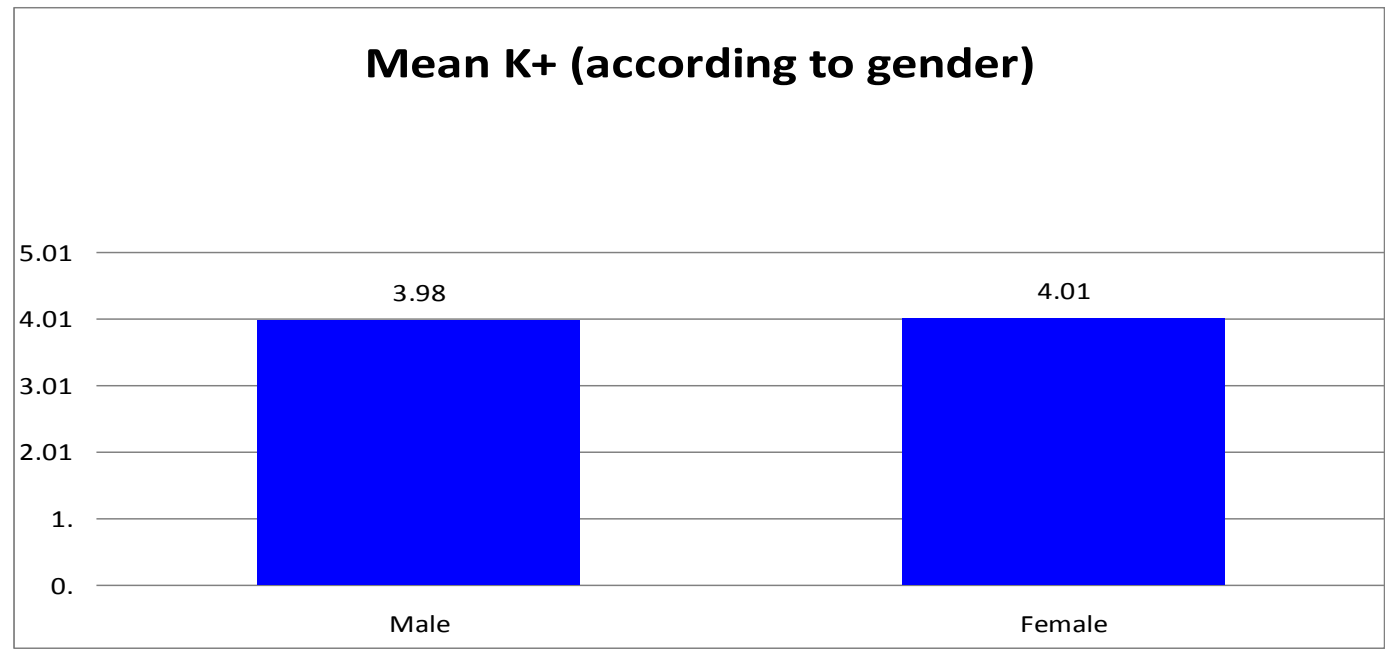


Figure 4 Graph showing mean Creatinine of hypertensive subjects according to gender

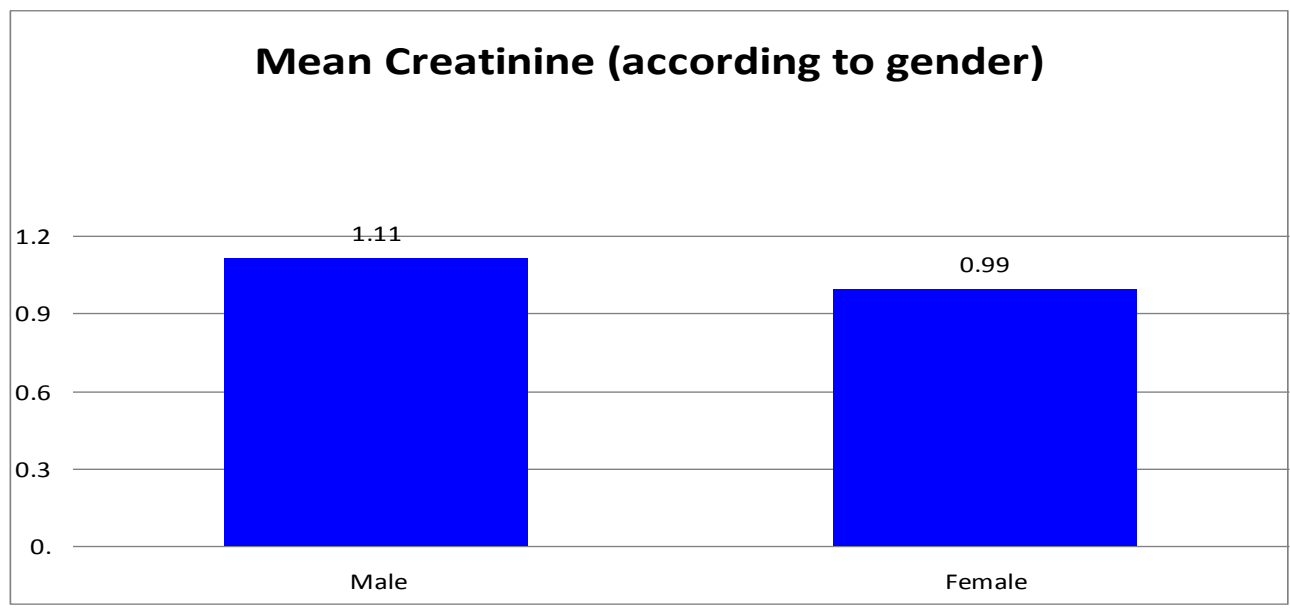

Figure 5 Graph showing mean UA of hypertensive subjects according to gender

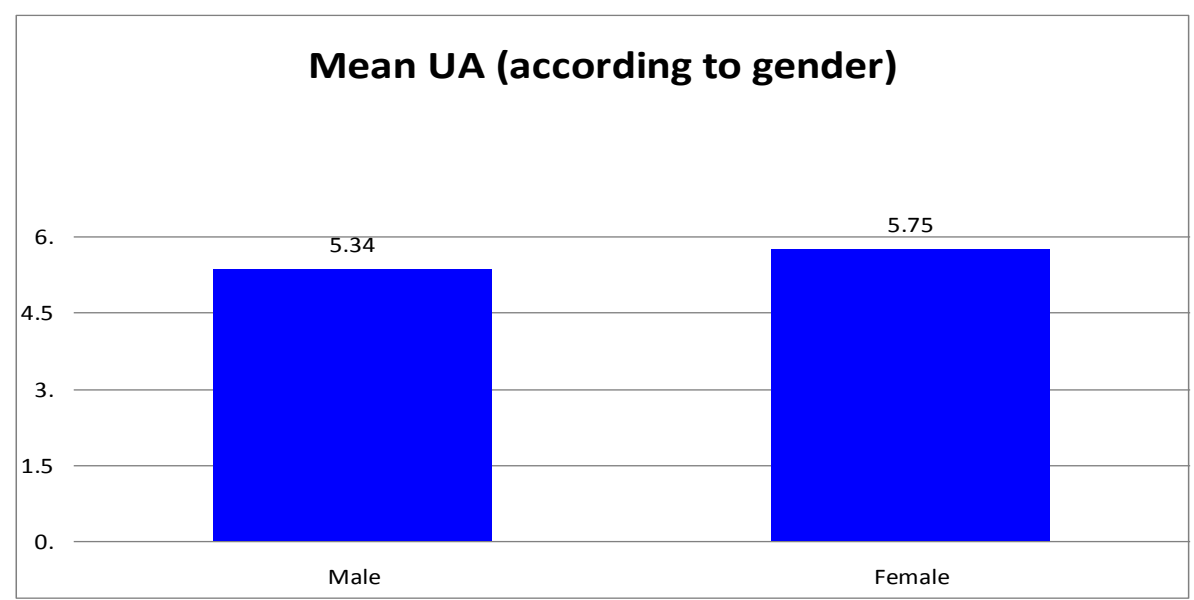

Figure 6 Graph showing mean FBS and PPBS of hypertensive subjects according to gender

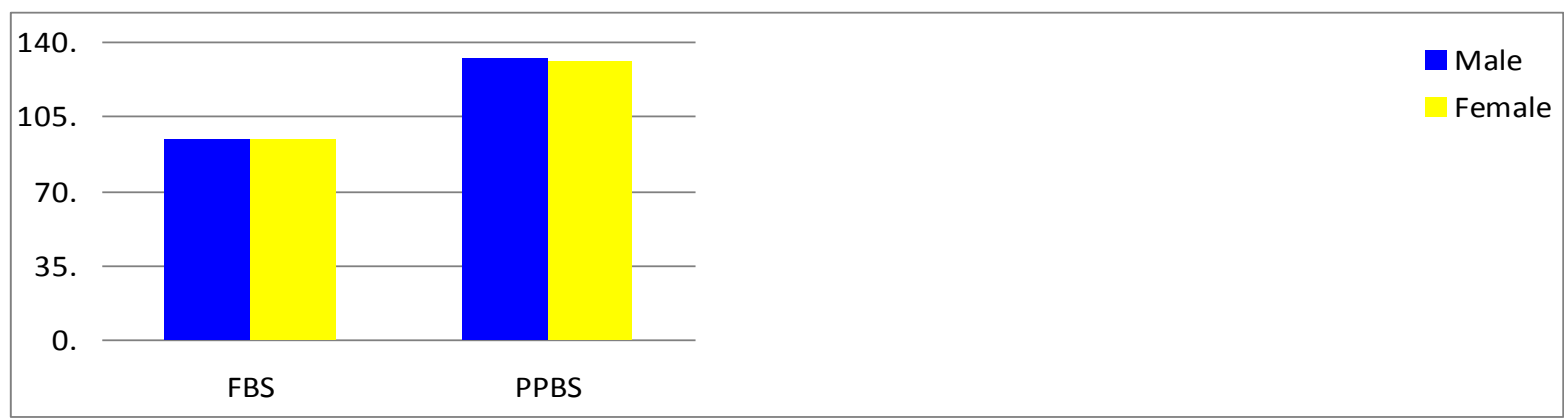

Figure 7 Graph showing mean CHL of hypertensive subjects according to gender

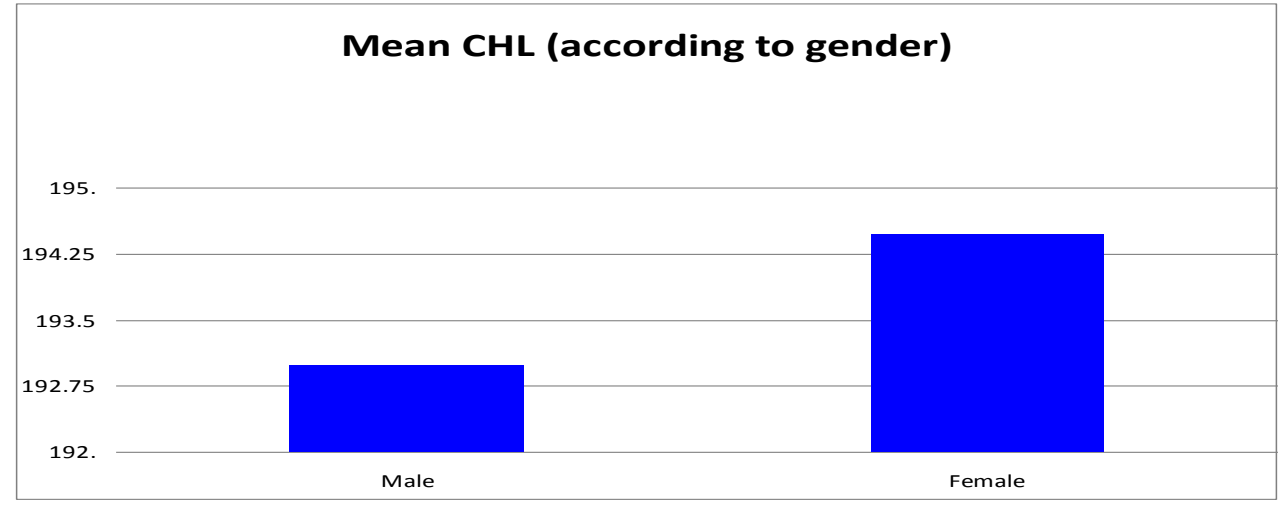


Figure 8 Graph showing mean TG of hypertensive subjects according to gender

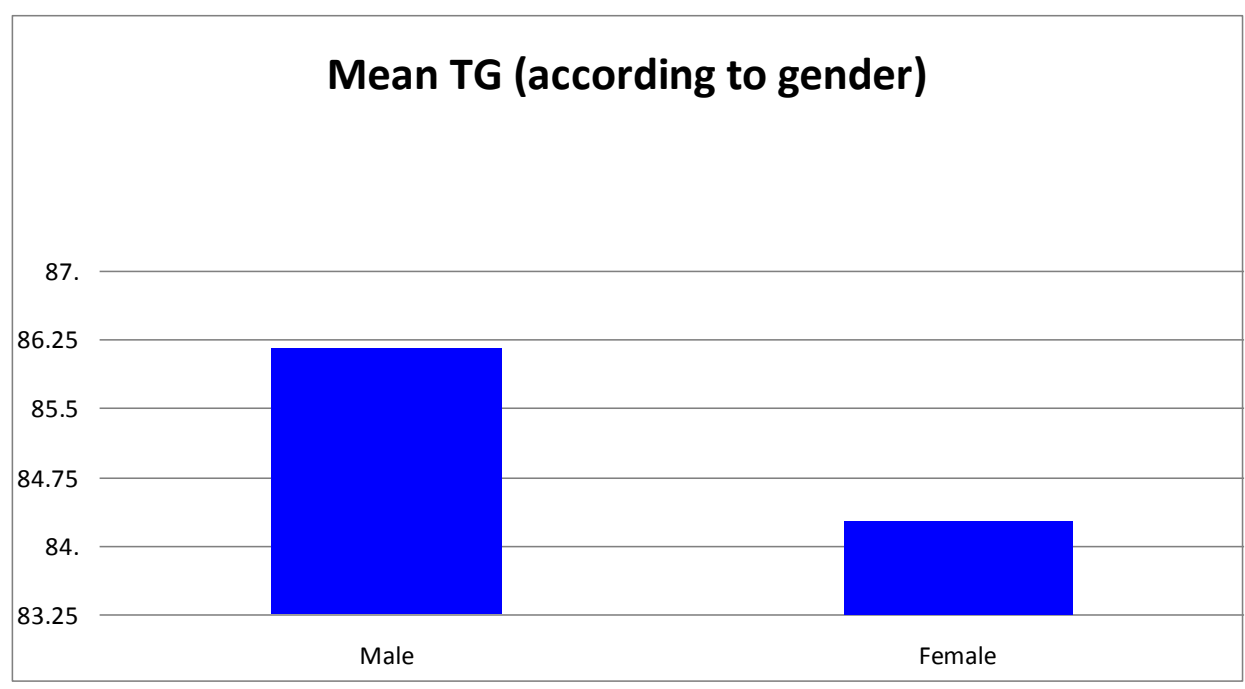

Figure 9 Graph showing mean HDL,VLDL, LDL of hypertensive subjects according to gender

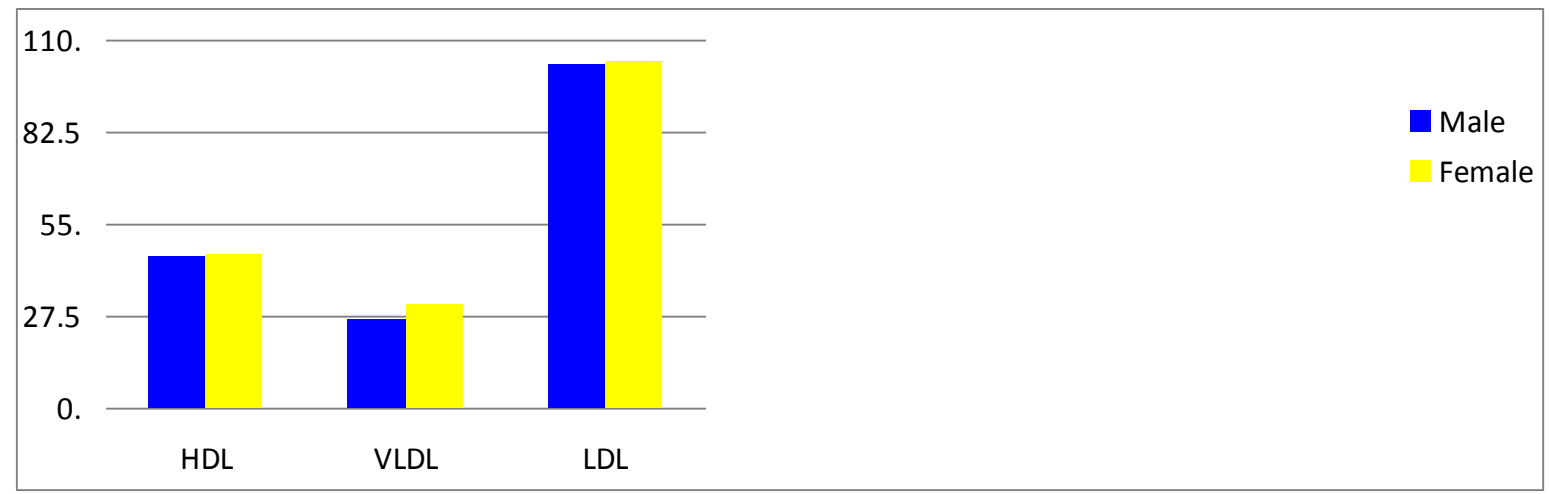

Table 10 Independent t-test result

\begin{tabular}{|l|c|c|c|c|c|}
\hline Sr. No. & Biochemical parameters & t-test & df & p-value & Mean Difference \\
\hline 1 & $\mathrm{Na}^{+}$ & -0.726 & 198 & 0.469 & -0.52029 \\
\hline 2 & $\mathrm{~K}^{+}$ & -0.482 & 198 & 0.631 & -0.02443 \\
\hline 3 & Creatinine & 2.114 & 198 & 0.036 & 0.12703 \\
\hline 4 & Uric Acid & -0.787 & 198 & 0.432 & -0.41615 \\
\hline 5 & FBS & 0.191 & 198 & 0.848 & 0.41964 \\
\hline 6 & PPBS & 0.638 & 198 & 0.524 & 1.71834 \\
\hline 7 & CHL & -0.371 & 198 & 0.711 & -1.48377 \\
\hline 8 & TG & 0.749 & 198 & 0.455 & 1.88799 \\
\hline 9 & HDL & -0.493 & 198 & 0.623 & -0.66964 \\
\hline 10 & VLDL & -3.696 & 198 & 0.000 & -4.71834 \\
\hline 11 & LDL & -0.289 & 198 & 0.773 & -1.24026 \\
\hline
\end{tabular}

\section{Interpretation}

p-value for creatinine and VLDL is less than that of 0.05 indicates significance of difference between average creatinine and VLDL of male and female. For all other parameters p-value is greater than that of 0.05 indicates no significance of difference.

Figure 11 Correlation of LVM with Biochemical variables in hypertensive subjects 


\begin{tabular}{|c|c|c|c|}
\hline \multirow{3}{*}{$\mathrm{Na}^{+}$} & Pearson Correlation & -.113 & \\
\hline & P-value & .110 & NS Negative \\
\hline & $\mathrm{N}$ & 200 & \\
\hline \multirow[t]{3}{*}{$\mathrm{K}^{+}$} & Pearson Correlation & $.256^{* *}$ & \\
\hline & P-value & .000 & Significant positive \\
\hline & $\mathrm{N}$ & 200 & \\
\hline \multirow[t]{3}{*}{ Creatinine } & Pearson Correlation & $.343^{* *}$ & \\
\hline & P-value & .000 & Significant Positive \\
\hline & $\mathrm{N}$ & 200 & \\
\hline \multirow[t]{3}{*}{ UricAcid } & Pearson Correlation & .016 & \\
\hline & P-value & .819 & NS Negative \\
\hline & $\mathrm{N}$ & 200 & \\
\hline \multirow[t]{3}{*}{ FBS } & Pearson Correlation & .108 & \\
\hline & P-value & .126 & NS Positive \\
\hline & $\mathrm{N}$ & 200 & \\
\hline \multirow[t]{3}{*}{ PPBS } & Pearson Correlation & .135 & \\
\hline & P-value & .056 & NS Positive \\
\hline & $\mathrm{N}$ & 200 & \\
\hline \multirow[t]{3}{*}{ CHL } & Pearson Correlation & .077 & \\
\hline & P-value & .276 & NS positive \\
\hline & $\mathrm{N}$ & 200 & \\
\hline \multirow[t]{3}{*}{ TG } & Pearson Correlation & -.006 & \\
\hline & P-value & .935 & NS Negative \\
\hline & $\mathrm{N}$ & 200 & \\
\hline \multirow[t]{3}{*}{ HDL } & Pearson Correlation & .003 & \\
\hline & P-value & .967 & NS Negative \\
\hline & $\mathrm{N}$ & 200 & \\
\hline \multirow[t]{3}{*}{ VLDL } & Pearson Correlation & -.051 & \\
\hline & P-value & .471 & NS Negative \\
\hline & $\mathrm{N}$ & 200 & \\
\hline \multirow[t]{3}{*}{ LDL } & Pearson Correlation & .098 & \\
\hline & P-value & .169 & NS positive \\
\hline & $\mathrm{N}$ & 200 & \\
\hline
\end{tabular}

\section{Interpretation}

1) P-value less than that of 0.05 with positive Pearson correlation value indicates significant positive correlation between $\mathrm{K}^{+}$and LVM.

2) P-value less than that of 0.05 with Negative Pearson correlation value indicates significant Negative correlation between none of Biochemical parameters and LVM.

3) P-value greater than that of 0.05 with positive Pearson correlation value indicates non-significant (NS) positive correlation between FBS, PPBS, CHL, LDL and LVM.

4) P-value greater than that of 0.05 with Negative Pearson correlation value indicates non-significant (NS) Negative correlation between $\mathrm{Na}^{+}$, Uric acid, TG, HDL, VLDL and LVM.
Present study was based on biochemical factors that affect left ventricular mass in patients with hypertension. This analysis revealed that there is significant positive correlation between biochemical parameter $\mathrm{K}^{+}$and creatinine with LVM with positive Pearson correlation and also there is a non-significant (NS) positive correlation between biochemical parameters (i.e. FBS, PPBS, CHL \& LDL) with LVM with positive Pearson correlation.

\section{References}

1. https://www.mayoclinic.org/diseases-cond itions/high-blood-pressure/symptoms-caus es/syc-20373410

2. http://www.heart.org/en/health-topics/hear t-valve-problems-and-disease/heart-valveproblems-and-causes/what-is-left-ventricul ar-hypertrophy-lvh

\section{Conclusion}


3. Kannel WB, Gordon T, Castelli WP, Margolis JR. . Electrocardiographic left ventricular hypertrophy and risk of coronary heart disease: the Framingham Study . Ann Intern Med 1970; 72:813-22.

4. Kannel WB, Schatzkin A. . Sudden death: lessons from subsets in population studies . J Am CollCardiol 1985; 5:Suppl:141B-149B.

5. Kannel WB, Dannenberg AL, Levy D. . Population implications of electrocardiographic left ventricular hypertrophy. Am J Cardiol 1987; 60:85I-93I.

6. Post WS, Larson MG, Levy D. Impact of left ventricular structure on the incidence of hypertension. The Framingham Heart Study. Circulation. 1994 Jul 1;90(1):179-85.

7. Koren MJ, Devereux RB, Casale PN, et al. Relation of left ventricular mass and geometry to morbidity and mortality in uncomplicated essential hypertension. Ann Intern Med 1991;114:345-52

8. de Simone G, Daniels SR, Devereux RB, et al. Left ventricular mass and body size in normotensive children and adults: assessment of allometric relations and impact of overweight. J Am Coll Cardiol 1992;20:1251-60.

9. de Simone G, Kizer JR, Chinali M, et al. Normalization for body size and population-attributable risk of left ventricular hypertrophy: the Strong Heart Study. Am J Hypertens 2005;18:191-6.

10. Lang RM, Badano LP, Mor-Avi V, et al. Recommendations for cardiac chamber quantification by echocardiography in adults: an update from the American Society of Echocardiography and the European Association of Cardiovascular Imaging. $J$ Am Soc Echocardiogr 2015;28:1-39.e14.

11. Teichholz LE, Kreulen T, Herman MV, Gorlin R Am J Cardiol. 1976 Jan; 37(1):7-11. 